https://doi.org/10.5817/OS2020-4-8

\title{
О функционировании, семантическом и прагматическом использовании фразем в заголовках медиатекстов
}

КАЛЕЧИЦ, Е.И.: Фразеологизмы в «действии»: семантико-прагматический аспект. Минск: Колорград, 2020. 350 с. ISBN 978-985-596-671-6.

Фразеологизмы являются составной частью каждого естественного языка на протяжении всей его истории, указывают на его богатство и разнообразие и в то же время отражают историю нации и её культуры. Изучение этих устойчивых единиц речи позволяет поднять качество нашего общения на более высокий уровень.

В настоящее время язык средств массовой информации в значительной степени определяет новые языковые стандарты: отражает изменения, происходящие в языке, и благодаря своей доступности и распространённости принимает на себя нормативную функцию. Кроме того, язык СМИ является идеальным учебным и научным материалом для исследований лингвистов, помогающим прояснить тенденции, которые имеют место в современных языках. Многие авторы совершенно справедливо отбирают материалы из различных СМИ с целью изучения трансформационных явлений во фразеологии.

На сегодняшний день признак устойчивости, характерный для фразеологизмов, при функционировании их в речи довольно часто не наблюдается. Так, может возникнуть несколько вариантов одной фраземы или её трансформации. Однако мы можем говорить об устойчивости фразеологизмов, проявляющейся преимущественно на структурном и семантическом уровнях. «Специфика фразеологической устойчивости - в сохранении структурно-семантической модели сочетания, а не в консервации одного единственного варианта» ${ }^{1}$. Изменения в устойчивых выражениях, происходящие в их фонетическом, словообразовательном и грамматическом плане, квалифицируются как варианты фразеологизмов. Причём исследования показали, что 35-40 \% идиом имеют различные вариантные формы ${ }^{2}$. Способность фразеологизмов изменяться является основой для создания не только вариантов и различных типов трансформаций фразем, но и для возникновения новых устойчивых идиом фразеологических неологизмов.

1 MOKIJENKO, V. M. i kol.: Russkaja frazeologija dlja nemcev. Sankt-Peterburg: Zlatoust, 2015, s. 12.

2 Cp. MLACEK, J.: Vymedzovanie frazeológie a $t z v$. frazeologická parametrizácia. In: Jazykovedný časopis, 1991, roč. 42, č. 1, s. 61. 
Независимо от жанра публицистики существует общая тенденция размещать фраземы и их модификационные аналоги в заголовках медиатекстов. Поскольку главные задачи заголовка - ясно и сжато указать читателю на тему и идею статьи и привлечь его внимание, неудивительно, что трансформации фразем здесь встречаются чаще всего.

В июле 2020 года в белорусском издательстве «Колорград» была издана монография «Фразеологизмы в «действии»: семантико-прагматический аспект», посвящённая «изучению письменных текстов, размещённых в Интернет-среде, а именно употреблению в них фразеологических единищ» ${ }^{3}$. Книга, представляющая собой отличную авторскую работу Е. И. Калечиц, кандидата филологических наук, доцента кафедры русистики Философского факультета Университета Константина Философа в Нитре, посвящена анализу письменных текстов, опубликованных на сайте «Российской газеты» (https://rg.ru/), в частности, функционированию, семантическому и прагматическому использованию фразем в заголовках медиатекстов. Данный анализ устойчивых фраз, используемых в медиатекстах, основан на современных научных взглядах, берущих начало в таких дисциплинах, как философия и лингвистика (в частности, стилистика, прагматика и медиалингвистика). Для описания использования идиом в языке журналистов Е. И. Калечиц использовала антропологический, диалогический, прагматический, дискурсивный и интенциональный подходы.

Основой рецензируемой нами работы Е.И. Калечиц послужил ряд теоретических положений, а именно: диалогизм М. М. Бахтина и разграничение жанров журналистики в соответствии с типом адресата, предложенные Л.Р. Дускаевой ${ }^{5}$; постулаты Т. Г. Винокур ${ }^{6}$, В.В. Дементьева ${ }^{7}$, А. Ю. Масловой ${ }^{8}$, Н. И. Формановской ${ }^{9}$ и других лингвистов, изучающих речевые модели и речевое поведение коммуникантов, отражённые в теории

3 KALEČIC, Je. I.: Frazeologizmy v «dejstvii»: semantiko-pragmatičeskij aspekt. Minsk: Kolorgrad, 2020, s. 6.

4 BACHTIN, M. M.: Problema soderžanija materiala i formy v slovesnom chudožestvennom tvorčestve. In: Voprosy literatury i èstetiki. Moskva: Chud. literatura, 1975; BACHTIN, M. M.: Èstetika slovesnogo tvorčestva. 2-je izd. Moskva: Iskusstvo, 1986.

5 DUSKAJEVA, L. R.: Dialogičeskaja priroda gazetnych rečevych žanrov. 2-je izd., dop., ispr. SPbGU: Filologičeskij fakul'tet, 2012; DUSKAJEVA, L. R.: Intencional'nost' mediareči: ontologija i struktura tipovoj intencii. In: Mediatekst kak poliintencional'naja sistema: sbornik statej. Sankt-Peterburg: Sankt-Peterburgskij gos. un-t, 2012.

6 VINOKUR, T. G.: Govorjaščij i slušajuščij: varianty rečevogo povedenija. Moskva: Nauka, 1993.

7 DEMENT'JEV, V. V.: Neprjamaja kommunikacija. Moskva: Gnozis, 2006.

8 MASLOVA, A. Ju.: Vvedenije v pragmalingvistiku: učeb. posobije. 3-je izd. Moskva: Flinta, 2010.

9 FORMANOVSKAJA, N. I.: Rečevoje obščenije: kommunikativno-pragmatičeskij podchod: učeb. posobije. Gos. in-t rus jaz. im. A. S. Puškina - Moskva: Russkij jazyk, 2002. 
речевого (коммуникативного) акта, которые вытекают из философских и коммуникативно-прагматических взглядов Дж. Л. Остина ${ }^{10}$ и Дж. Р. Сёрля ${ }^{11}$. Кроме того, в книге учитываются основные идеи теории текста, сформулированные в трудах Н. С. Валгиной ${ }^{12}$, И. Р. Гальперина ${ }^{13}$, Ю. Н. Земской ${ }^{14}$, Я. Соколовой ${ }^{15}$ и др. Автор исследования - Е.И.Калечиц, - вслед за другими учёными, считает медиатекст и медиадискурс основными концептуальными понятиями медиалингвистики, содержание которых продолжает подвергаться анализу и уточнениям в работах лингвистов из различных славянских стран. В то же время в данной монографии автор использует новый подход к интерпретации медиатекста как многоцелевой системы, развиваемый, как правило, российскими учёными.

Представленная монография Е.И. Калечиц, отличающаяся чёткостью композиции и продуманной структурой, состоит из пяти разделов, включающих несколько подразделов. Составные части монографии - введение ${ }^{16}$, заключение $^{17}$, словацкое резюме ${ }^{18}$, английское резюме ${ }^{19}$, а также список использованной литературы, в том числе словари, энциклопедии и электронные ресурсы ${ }^{20}$.

С точки зрения методологии в рецензируемой нами работе Е. И. Калечиц применила различные методы исследования, соответствующие поставленным целям и задачам. К ним относятся методы лингвистического анализа (семантический и синтаксический), в частности приёмы структурно-семантического моделирования фразем и динамического анализа прагмем, описательные методы (восприятие, сравнение и классификация), а также статистический, дискурсивный, когнитивный анализы и метод критической лингвистики.

10 OSTIN, Dž. L.: Slovo kak dejstvije. In: Novoje v zarubežnoj lingvistike. Vyp. XVII. Teorija rečevych aktov. Moskva: Progress, 1986.

11 SERL', Dž. R.: Kosvennyje rečevyje akty. In: Novoje v zarubežnoj lingvistike: sbornik statej. Vyp. 17. Moskva: Progress, 1986; SERL', Dž. R.: Čto takoje rečevoj akt. In: Novoje v zarubežnoj lingvistike: sbornik statej. Vyp. 17. Moskva: Progress, 1986.

12 VALGINA, N. S.: Teorija teksta: učeb. posobije. Moskva: Logos, 2003.

13 GAL'PERIN, I. R.: Tekst kak ob”jekt lingvističeskogo issledovanija. 5-je izd. Moskva: KomKniga, 2007.

14 ZEMSKAJA, Ju. N. i dr.: Teorija teksta: učeb. posobije. Moskva: Flinta, 2010.

15 SOKOLOVA, Ja.: Konstrukcii social'noj samoidentifikacii i samoprezentacii govorjaščego: Očerki ob ègocentričeskich sredstvach slovackogo jazyka. Mauritius: Palmarium Academic Publishing, 2019.

16 KALEČIC, Je. I.: Frazeologizmy $v$ «dejstvii»: semantiko-pragmatičeskij aspekt. Minsk: Kolorgrad, 2020, s. $6-14$.

17 Ibidem, s. 277-289.

18 Ibidem, s. 290-303.

19 Ibidem, s. 304-317.

20 Ibidem, s. 318-348. 
Хочется отметить, что благодаря правильно отобранной методике анализа собранного материала автору монографии в целом удалось достигнуть поставленной цели: «проанализировать процессы и механизмы семантической динамики, происходящие в устойчивых выражениях, встречающихся в совокупном дискурсе «Российской газеты», и выявить модели структурно-семантических преобразований фразем с учётом интертекстуальных, прагматических и функционально-стилистических регистров медиатекста» ${ }^{21}$.

В первом разделе (Содержание понятия медиатекст и виды медиатекстов), кроме интерпретации понятий текст, медиатекст и медиадискурс, Е.И. Калечиц приводит историю и причины возникновения термина медиатекст в лингвистике, далее языковед затрагивает проблематику сфер его функционирования и основных категорий (медийности, массовости, интегративности, поликодовости и открытости текста на содержательно-смысловом, композиционно-структурном и знаковом уровнях). Автором представлены различные типологии медиатекстов, однако Е. И. Калечиц, склоняется к позиции Л. М. Майдановой и С. О. Калгановой ${ }^{22}$, по той причине, что «она достаточно прозрачна и указывает на конечную цель создания произведения» ${ }^{23}$. В подразделе 1.3, кроме характеристики понятий интертекстуальность, ирония и языковая игра «как ключевых составляющих Интернет-текстов» ${ }^{24}$, автор демонстрирует данные элементы современного медиатекста наглядным иллюстративным материалом. В подразделе 1.4 Е.И. Калечиц рассматривает, на наш взгляд, интересную и не так часто обсуждаемую лингвистами тему адресации, связанную с проблематикой субъектов медиакоммуникации: автора и адресата. Причём она подтверждает вывод других учёных, что «в настоящее время в медиатексте отношения адресанта и адресата приобретают инверсионный характер» ${ }^{25}$. Рассматривая тенденцию снятия дистанции между адресантом и адресатом в медиадискурсе, мы согласны с мнением Е. И. Калечиц, которая делает вывод, «что авторство современных медиатекстов приписывается либо конкретному человеку, либо определённому или обобщённому коллективу. На этом основании в медиалингвистике принято говорить о двойном субъекте - пишущем текст и обрабатывающем его с учётом мнений и убеждений

21 Ibidem, s. 11.

22 MAJDANOVA, L. M. - KALGANOVA, S. O.: Žanry žurnalistiki: praktičeskaja stilistika: èlektronnoje učebnoje posobije. [Èlektronnyj resurs]. [cit. 23. 10. 2020]. Jekaterinburg: ANO VO «Gumanitarnyj universitet», 2017.

23 KALEČIC, Je. I.: Frazeologizmy $v$ «dejstvii»: semantiko-pragmatičeskij aspekt. Minsk: Kolorgrad, 2020, S. 25 .

24 Ibidem, s. 12.

25 Ibidem, s. 36. 
той группы людей, представителем которой он выступает в данный отрезок времени» ${ }^{26}$. Автор в своей работе приводит похожие мнения Т. Л. Каминской и Н. В. Соловьёвой, согласно которым «в современной коммуникационной ситуации роль адресата приравнивается к роли автора» ${ }^{27}$ и рассматривается «как ведущий текстообразующий фактор медиакоммуникации, обусловливающий стилистико-языковую и жанровую специфику медиатекстов» ${ }^{28}$. В данном подразделе Е. И. Калечиц также обращает своё внимание на массового адресата «Российской газеты», называя его «представителем образцовой среды». В части 1.5 автор рецензируемого исследования, сосредотачивая своё внимание на характеристике Интернет-медиа и их классификацию, описывает структуру веб-медиатекста «Российской газеты» и анализирует особенности его функционирования.

Во введении ко второму разделу (Функиионирование фразеологизмов в медиатекстах) Е.И. Калечиц опирается на работы известных словацких, русских, украинских и белорусских лингвистов в освещении проблематики устойчивости и воспроизводимости фразеологизмов, где учёные описывали их «семантические, структурные и грамматические особенности и преобразования в основном с лингвокультурологического и этнолингвистического аспектов» ${ }^{29}$. При этом автор сравнивает данную точку зрения с изучением фразем в рамках коммуникативно- и когнитивно-прагматического подходов. В подразделе 2.1 Е.И.Калечиц даёт трактовку узкого ${ }^{30}$ и более широкого ${ }^{31}$ понимания

26 Ibidem, s. 40.

27 KAMINSKAJA, T. L.: Avtor i adresat v sovremennych mediatekstach [Èlektronnyj resurs]. [cit. 23. 10. 2020]. In: Vestnik Sankt-Peterburgskogo un-ta, ser. 9, Jazyk i literatura, vyp. 2, 2008, č. II, s. 316.

28 SOLOV'JEVA, N.V.: Sovremennyje mediateksty $v$ aspekte stileobrazujuščich kategorij «Avtor» $i$ «Adresat» [Èlektronnyj resurs]. [cit. 23. 10. 2020]. In: Vestnik Čeljabinskogo gos. un-ta. Ser. Filologija, iskusstvovedenije, 2012, vyp. 71, № 32 (286), s. 107.

29 KALEČIC, Je. I.: Frazeologizmy v «dejstvii»: semantiko-pragmatičeskij aspekt. Minsk: Kolorgrad, 2020, S. 54 .

30 ALEFIRENKO, N. F. - SEMENENKO, N. N.: Frazeologija i paremiologija: učeb. posobije. Moskva: Flinta-Nauka, 2009; ALEFIRENKO, N.F. i dr.: Sovremennaja frazeologija: tendencii i innovacii: monografija. Moskva-Sankt-Peterburg-Brjansk: Novyj projekt, 2016; MOLOTKOV, A. I.: Osnovy frazeologii russkogo jazyka. AN SSSR, In-t rus. jaz. - Leningrad: Nauka. Leningr. otd-nije, 1977; ŽUKOV, V.P. - ŽUKOV, A. V.: Russkaja frazeologija: učeb. posobije. 2-je izd., ispr. i dop. Moskva: Vysšaja škola, 2006 и др.

31 BULACHOVSKIJ, L. A.: Vvedenije v jazykoznanije: Čast' 2. Moskva: Učpedgiz, 1954; BARANOV, A.N. - DOBROVOL'SKIJ, D. O.: Osnovy frazeologii. 2-e izd. Moskva: Flinta, 2014; ARCHANGEL'SKIJ, V.L.: Ustojčivyje frazy v sovremennom russkom jazyke: Osnovy teorii ustojčivych fraz i problemy obščej frazeologii. Rost. n/D gos. ped. in-t. - Rostov n/D: Izd-vo Rost. un-ta, 1964; ŠANSKIJ, N. M.: Frazeologija sovremennogo russkogo jazyka: učeb. posobije. 6-je izd. Moskva: Librokom, 2012 и т. д. 
предмета изучения фразеологии. В подразделе 2.2 автор представляет основную характеристику фразеологизмов, их внешние и внутренние признаки, упоминает об их вариантности. На основе своих наблюдений и анализа фразеографических источников в данном подразделе Е. И. Калечиц приводит наглядные примеры наиболее продуктивных в языке лексических и грамматических типов вариантов фразеологических единиц. В подразделе 2.3 в рамках коммуникативно-прагматического аспекта изучения интертекстуальности автор монографии называет устойчивые единицы самым распространённым на сегодняшний день в лингвистике термином интертекстема, который и применяет в своей работе. По её мнению, данное понятие «имеет явные мотивационные признаки межтекстовости и взаимодействия, отсутствующие у других похожих по семантике специальных наименований» ${ }^{32}$. Автор, опираясь на другие работы учёных, различает актуальные и культурологические интертекстемы, а в своём исследовании рассматривает «только культурологические интертекстемы, отождествляемые с различными устойчивыми единицами языка - фразеологизмами в широком смысле» ${ }^{33}$. В подразделе 2.4 Е. И. Калечиц затрагивает проблематику роли интенций в текстообразовании медийных речевых актов. На основе рассматриваемой письменной формы медиаречи (веб-медиатекстов) автор в своей работе обращает внимание, прежде всего, на «иллокутивную фазу речевого акта, авторские интенции» ${ }^{34}$. Опираясь на классификацию Н. И. Формановской ${ }^{35}$, Е. И. Калечиц рассматривает семь типов речевых актов, которые наблюдает «в совокупном дискурсе „Российской газеты“» (с. 72) и представляет их в последующих разделах и подразделах рецензируемой нами работы. В подразделе 2.5 автор данного исследования обсуждает проблему выделения типов фразеологизмов-интертекстем, описывая общие модели образования новых интертекстем либо их вариантов.

Во введении к третьему разделу (Прагматическое использование фразеологизмов в медиатекстах «Российской газеты») Е.И. Калечиц подтверждает свою гипотезу об активности использования журналистами представленных единицах языка - фразеологизмах - в заголовках и самом содержании современных медиатекстов «Российской газеты». В подразделе 3.1 Е. И. Калечиц приводит трактовки некоторых лингвистов по поводу понятий заголовок и реклама, причём автор утверждает, что по форме и содержанию «реклама

32 KALEČIC, Je. I.: Frazeologizmy v «dejstvii»: semantiko-pragmatičeskij aspekt. Minsk: Kolorgrad, 2020, s. $65-66$.

33 Ibidem, s. 63.

34 Ibidem, s. 69.

35 FORMANOVSKAJA, N. I.: Rečevoje obščenije: kommunikativno-pragmatičeskij podchod: učeb. posobije. Gos. in-t rus jaz. im. A. S. Puškina - Moskva: Russkij jazyk, 2002. 
и медиатекст, в том числе и его заголовок, сближаются» ${ }^{36}$, поскольку заголовок является «всегда самой сильной позицией в тексте, особенно когда в его роли выступают интертекстемы» ${ }^{37}$. В начале подраздела 3.2 на основе собранного фактического материала - заголовков «Российской газеты» - Е.И. Калечиц анализирует функционирующие в веб-медиатекстах интертекстемы, не подвергнувшиеся каким-либо семантическим изменениям, с позиции отражения интенций, влияющих на типы письменных речевых актов, которые соответствуют репрезентативам, коммисивам и экспрессивам ${ }^{38}$. В первой части данного подраздела Е.И. Калечиц рассматривает прямые интенции адресанта в заголовках-интертекстемах, не только сохранивших «буквальный смысл» своих компонентов (буквализацию значения), но и семантически модифицированных. На основе проанализированного материала Е. И. Калечиц приходит к выводу, что «авторские преобразования устойчивых сочетаний оказывают влияние на выражение прямых интенций адресанта, которые, как правило, реализуются на уровне заголовков и наиболее часто проявляются в экспрессивных и реже в репрезентативных, комиссивных и рогативных типах речевых актов» ${ }^{39}$. Во второй части подраздела 3.2 Е. И. Калечиц рассматривает заголовки-интертекстемы, выражающие косвенные интенции адресанта, т. е. те продуктивные приёмы, при которых происходят структурно-семантические изменения в устойчивых выражениях, используемых для образования интертекстем в «Российской газете». К таким приёмам автор относит экспликацию, лексическую субституцию, импликацию и изменение грамматической (в том числе синтаксической) структуры фразеологизма. Можно высоко оценить то, что автор работы на основе экземплификационных заголовков анализирует встречающиеся в них и более сложные модификации (комплексные трансформации) интертекстем, которые распределяет в шесть групп согласно типу модификации. Проведённый Е. И. Калечиц статистический анализ показал (он является вполне убедительным и не вызывает у нас сомнения), что «употребляемые в медийной речи фразеологизмы часто подвергаются структурно-семантическим изменениям» ${ }^{40}$. Кроме того, наглядным и доказательным является вывод, что «эти трансформации в «Российской газете» очень редко приводят к потере связи между устойчивым сочетанием и заголовком, чаще

36 KALEČIC, Je. I.: Frazeologizmy v «dejstvii»: semantiko-pragmatičeskij aspekt. Minsk: Kolorgrad, 2020, S. 72.

37 Ibidem, s. 82.

38 Ibidem, s. 86.

39 Ibidem, s. 97.

40 Ibidem, s. 144. 
они сохраняют общиость значения, которое выявляется при анализе полного содержания медиатекста» (там же).

В четвёртом разделе (Прагматическое использование устойчивых выражений, близких по своей природе к фразеологизмам, в веб-медиатекстах «Российской газеты») Е.И.ККалечиц анализирует устойчивые выражения, похожие на фразеологизмы, на основе тщательно отобранного фактического материала из веб-медиатекстов «Российской газеты» ${ }^{41}$. Например, в подразделе 4.1 речь идёт об устойчивых сравнениях (компаративных фразеологизмах и закрепившихся в языке стереотипных конструкциях); о функционировании интертекстем, образованных от крылатых выражений и афоризмов, рассказывается в подразделе 4.2; использованию интертекстем-паремий в качестве заголовков «Российской газеты» посвящён подраздел 4.3; об индивидуально-авторских и традиционных интертекстемах-перифразах, употребляемых в заголовках медиатекстов, написано в подразделе 4.4. Перечисленные устойчивые единицы речи автор понимает как «выражения, имеющие идиоматические особенности воспроизводимости, образности и номинативности» (там же).

В пятом разделе (Употребление специальной лексики в роли заголовков-интертекстем) автор освещает проблематику употребления в качестве заголовков-интертекстем составных научных понятий (составных терминов), «так как по своей структуре (они имеют не менее двух компонентов) и по признакам устойчивости и воспроизводимости в речи их можно сравнить с фразеологизмами» ${ }^{42}$. В подразделе 5.1 автор отмечает употребление в роли интертекстем военной и морской терминологии, экономической и математической (подраздел 5.2), общественно-политической (подраздел 5·3), компьютерной (подраздел 5.4), спортивной (подраздел 5.5), юридической (подраздел 5.6), профессиональной лексики журналистов (подраздел 5.7) и понятий географической терминологии (подраздел 5.8).

В заключительной части рецензируемой нами монографической работы Е.И. Калечиц подводит итоги проведённого исследования.

Следует отметить несомненную актуальность темы работы, достоинством которой является проанализированный автором репрезентативный по количеству и качеству новый фактический материал из «Российской газеты» как «совокупного медиадискурса за период 2018 г. с учётом его прагматических и образно-номинативных средств категоризации с позиций интертекстуальности и семантической неологизации журналистских текстов» ${ }^{43}$.

\footnotetext{
41 Ibidem, s. 146.

42 Ibidem, s. 239.

43 Ibidem, s. 10.
} 
Таким образом, ещё раз хочется отметить, что книга, изданная Е. И. Калечиц, отличается чёткостью композиции, продуманным расположением материала, написана соответствующим научным и одновременно доступным языком. Автору в полной мере удалось рассмотреть вышеназванную проблематику, при этом Е.И. Калечиц показала глубокие знания в освещаемых вопросах и продемонстрировала умение работать с источниками, поэтому, как нам кажется, её монография имеет большое теоретическое и практическое значение. Кроме того, рецензируемая нами монография Е. И. Калечиц, безусловно, займёт достойное место среди исследований в области семиотики, прагматики, фразеологии и медиалингвистики. Материалы данного исследования могут быть полезны не только для лингвистов, журналистов и аспирантов филологических и журналистских специальностей, но также для специалистов по фразеологии, медиалингвистике и эголингвистике.

В целом эта качественно и профессионально написанная работа, которая производит положительное впечатление и поэтому заслуживает своего места и надлежащего внимания среди других публикаций, направленных на изучение и освещение аналогичных проблем в лингвистике.

Следовательно, монография Е.И. Калечиц без сомнения представляется серьёзной и очень интересной авторской работой, которая, на наш взгляд, окажет позитивное влияние на дальнейшие исследования медиадискурса.

Ян Галло

\section{Библиография:}

ALEFIRENKO, N. F. - SEMENENKO, N. N.: Frazeologija i paremiologija: učeb. posobije. Moskva: Flinta-Nauka, 2009. 342 s. ISBN 978-5-9765-0838-5.

ALEFIRENKO, N. F. i dr.: Sovremennaja frazeologija: tendencii i innovacii: monografija. Moskva-Sankt-Peterburg-Brjansk: Novyj projekt, 2016. 198 s. ISBN 978-5-9908370$-0-3$.

ARCHANGEL'SKIJ, V.L.: Ustojčivyje frazy v sovremennom russkom jazyke: Osnovy teorii ustojčivych fraz i problemy obščej frazeologii. Rost. n/D gos. ped. in-t. - Rostov n/D: Izd-vo Rost. un-ta, 1964. 315 s.

BACHTIN, M. M.: Èstetika slovesnogo tvorčestva. 2-je izd. Moskva: Iskusstvo, 1986. $444 \mathrm{~s}$.

BACHTIN, M. M.: Problema soderžanija materiala i formy v slovesnom chudožestvennom tvorčestve. In: Voprosy literatury i èstetiki. Moskva: Chud. literatura, 1975, s. 6-71. 
BARANOV, A. N. - DOBROVOL'SKIJ, D. O.: Osnovy frazeologii. 2-e izd. Moskva: Flinta, 2014. 310 s. ISBN 978-5-9765-1567-3.

BULACHOVSKIJ, L. A.: Vvedenije v jazykoznanije: Čast’ 2. Moskva: Učpedgiz, 1954. $177 \mathrm{~s}$.

DEMENT'JEV, V. V.: Neprjamaja kommunikacija. Moskva: Gnozis, 20o6. 374 s. ISBN 5-7333-0181-3.

DUSKAJEVA, L. R.: Dialogičeskaja priroda gazetnych rečevych žanrov. 2-je izd., dop., ispr. SPbGU: Filologičeskij fakul'tet, 2012. 274 s. ISBN 978-584-6512-429.

DUSKAJEVA, L. R.: Intencional'nost' mediareči: ontologija i struktura tipovoj intencii. In: Mediatekst kak poliintencional'naja sistema: sbornik statej. Sankt-Peterburg: Sankt-Peterburgskij gos. un-t, 2012, s. 10-16.

FORMANOVSKAJA, N. I.: Rečevoje obščenije: kommunikativno-pragmatičeskij podchod: učeb. posobije. Gos. in-t rus jaz. im. A.S. Puškina - Moskva: Russkij jazyk, 2002. 213 s. ISBN 5-200-03192-3.

GAL'PERIN, I. R.: Tekst kak ob”jekt lingvističeskogo issledovanija. 5-je izd. Moskva: KomKniga, 2007. 144 s. ISBN 978-5-484-00854-4.

KALEČIC, Je. I.: Frazeologizmy v «dejstvii»: semantiko-pragmatičeskij aspekt. Minsk: Kolorgrad, 2020. 350 s. ISBN 978-985-596-671-6.

KAMINSKAJA, T.L.: Avtor $i$ adresat $v$ sovremennych mediatekstach [Èlektronnyj resurs]. [cit. 23. 10. 2020]. In: Vestnik Sankt-Peterburgskogo un-ta, ser. 9, Jazyk i literatura, vyp. 2, 2008, č. II, s. 314-319. Režim dostupa: https:/cyberleninka.ru/ article/n/avtor-iadresat-v-sovremennyh-mediatekstah.

MAJDANOVA, L. M. - KALGANOVA, S. O.: Žanry žurnalistiki: praktičeskaja stilistika: èlektronnoje učebnoje posobije. [Èlektronnyj resurs]. [cit. 23. 10. 2020]. Jekaterinburg: ANO VO «Gumanitarnyj universitet», 2017. 334 s. ISBN 978-5-7741-0308-9.

MASLOVA, A. Ju.: Vvedenije v pragmalingvistiku: učeb. posobije. 3-je izd. Moskva: Flinta, 2010. 152 s. ISBN 978-5-89349-946-9.

MLACEK, J.: Vymedzovanie frazeológie a tzv. frazeologická parametrizácia. In: Jazykovedný časopis, 1991, roč. 42, č. 1, s. 53-64.

MOKIJENKO, V. M. i kol.: Russkaja frazeologija dlja nemcev. Sankt-Peterburg: Zlatoust, 2015. 231 s. ISBN 978-5-86547-892-8.

MOLOTKOV, A. I.: Osnovy frazeologii russkogo jazyka. AN SSSR, In-t rus. jaz. Leningrad: Nauka. Leningr. otd-nije, 1977. $283 \mathrm{s.}$

OSTIN, Dž. L.: Slovo kak dejstvije. In: Novoje v zarubežnoj lingvistike. Vyp. XVII. Teorija rečevych aktov. Moskva: Progress, 1986, s. 22-129.

SERL', Dž. R.: Čto takoje rečevoj akt. In: Novoje v zarubežnoj lingvistike: sbornik statej. Vyp. 17. Moskva: Progress, 1986, s. 151-169.

SERL', Dž. R.: Kosvennyje rečevyje akty. In: Novoje v zarubežnoj lingvistike: sbornik statej. Vyp. 17. Moskva: Progress, 1986, s. 195-222. 
SOKOLOVA, Ja.: Konstrukcii social'noj samoidentifikacii i samoprezentacii govorjaščego: Očerki ob ègocentričeskich sredstvach slovackogo jazyka. Mauritius: Palmarium Academic Publishing, 2019. 130 s. ISBN 978-620-2-38404-9.

SOLOV’JEVA, N. V.: Sovremennyje mediateksty v aspekte stileobrazujuščich kategorij «Avtor» $i$ «Adresat»[Èlektronnyj resurs]. [cit. 23. 10. 2020]. In: Vestnik Čeljabinskogo gos. un-ta. Ser. Filologija, iskusstvovedenije, 2012, vyp. 71, № 32 (286), s. 107-111. Režim dostupa: https://cyberleninka.ru/article/n/sovremennyemediatekstyv-aspekte-stileobrazuyuschih-kategoriy-avtor-i-adresat.

ŠANSKIJ, N. M.: Frazeologija sovremennogo russkogo jazyka: učeb. posobije. 6-je izd. Moskva: Librokom, 2012. 272 s. ISBN 978-539-7023-184.

VALGINA, N. S.: Teorija teksta: učeb. posobije. Moskva: Logos, 2003. 278 s. ISBN 5-94010$-187-9$.

VINOKUR, T. G.: Govorjaščij i slušajuščij: varianty rečevogo povedenija. Moskva: Nauka, 1993. 172 s. ISBN 5-02-011563-0.

ZEMSKAJA, Ju. N. i dr.: Teorija teksta: učeb. posobije. Moskva: Flinta, 2010. 132 s. ISBN 978-5-9765-0841-5 (Flinta), 978-5-02-037163-7 (Nauka).

ŽUKOV, V.P. - ŽUKOV, A. V.: Russkaja frazeologija: učeb. posobije. 2-je izd., ispr. i dop. Moskva: Vysšaja škola, 2006. 408 s. ISBN 5-06-005399-7.

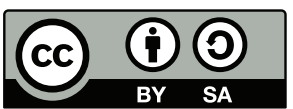

This work can be used in accordance with the Creative Commons BY-SA 4.0 International license terms and conditions (<https://creativecommons.org/licenses/by-sa/4.0/legalcode>). This does not apply to works or elements (such as images or photographs) that are used in the work under a contractual license or exception or limitation to relevant rights.

\section{https://doi.org/10.5817/0S2020-4-9}

\section{Sborník k nedožitým devadesátým narozeninám profesora Stanislava Žaži}

GAZDA, J. (ed.): Př́spěvky k aktuálním otázkám jazykovědné rusistiky (5): pragmatika syntax - sémantika. Brno: Jan Sojnek - Galium, 2020. 127 s. ISBN 978-80-88296-09-6.

Dne 5. srpna 2018 se uzavřela životní cesta předního českého rusisty a slavisty prof. PhDr. Stanislava Žaži, CSc. U př́ležitosti jeho 9o. narozenin ( ${ }^{*} 14.4$. 1929) uspořádal Ústav slavistiky Filozofické fakulty Masarykovy univerzity ve spolupráci a s podporou České asociace slavistů a Středoevropského centra slovanských studií dne 10. 5. 2019 jednodenní kolokvium nazvané Aktuální otázky současné jazykovědné 